\author{
Glenda Ernst ${ }^{1}$, Fernando Grassi ${ }^{1}$ and \\ Julio F Chertcoff ${ }^{2 *}$ \\ ${ }^{1}$ Pulmonary Lab, British Hospital from Buenos Aires, \\ $C A B A$, Argentina \\ ${ }^{2}$ Intensive Care Unit, British Hospital from Buenos \\ Aires, CABA, Argentina \\ Dates: Received: 04 January, 2016; Accepted: 27 \\ January, 2016; Published: 29 January, 2016 \\ *Corresponding author: Julio F. Chertcoff, Intensive \\ Care Unit, British Hospital from Buenos Aires, CABA \\ Argentina, Perdriel $74,1^{\circ}$ Floor. CP $1280 \mathrm{AEB}$, Tel: \\ (5411) 43096400; Ext 2808; E-mail: fchertcoff@ \\ yahoo.com.ar \\ www.peertechz.com \\ Keywords: Hepatopulmonary syndrome; \\ Portopulmonary hypertension; Liver transplant
}

\author{
Case Report
}

\section{Hepatopulmonary Syndrome and Portopulmonary Hypertension in the Same Patient}

\section{Abstract}

Hepatopulmonary syndrome (HPS) and portopulmonary hypertension (POPH) are the most common pulmonary vascular complications in patients with liver disease. We present a 71-year old woman with alcoholic cirrhosis and 6 month history of progressive shortness of breath with mild hypoxemia at rest. Results of spirometry was normal and diffusing capacity of the lung for carbon monoxide (DLCO) was severity reduced. Echocardiography with contrast enhancement revealed extra cardiac shunt. Three months after her initial presentation, a new echocardiography was performed with pulmonary systolic pressure increased and in a right heart catheterization (RHC) the mean pulmonary arterial pressure (PAPm) was $50 \mathrm{mmHg}$, this evidence supported the diagnosis of severe portopulmonary hypertension after HPS.

We consider that patients with HPS can develop POPH during the waiting time for liver transplant. Moderate and severe POPH represents a contraindication for liver transplantation because it could lead to an unacceptable mortality rate. Screening for $\mathrm{POPH}$ is relevant in patients while waiting for liver transplant.
\end{abstract}

\section{Abbreviations}

HPS: Hepatopulmonary Syndrome; POPH: Portopulmonary Hypertension; RHC: Right Heart Catheterization; PAPm: Pulmonary Arterial Pressure

\section{Introduction}

Association of chronic liver disease with respiratory symptoms and hypoxia is well recognized, owing to the success of liver transplantation, there has been increasing the importance of recognition of pulmonary vascular complications of hepatic disease states [1]. Hepatopulmonary syndrome (HPS) and portopulmonary hypertension (POPH) are relatively common complications in patients among liver transplantation candidates [2]. HPS and POPH can share similar respiratory symptoms, though the physiology is different and both are considered mutually exclusive.

Pathophysiology of these two entities could be related with an imbalance between vasoconstrictor and vasodilator [3]. Angiogenic factors that escape from hepatic metabolism could play a role in the pulmonary circulation through collateral shunts and the pathogenesis of POPH [4]. HPS has been defined as an oxygenation defect caused by the development of intrapulmonary vascular dilatation in patients with either advanced liver disease and/or portal hypertension [5]. While POPH is characterized by an increase in the pulmonary vascular resistance as a consequence of obstruction to pulmonary arterial blood flow with or without advanced liver disease [6], the main feature of HPS is vasodilatation.

The role of liver transplantation in reversing these vascular disorders is controversial, although complete resolution of HPS and, less frequently, POPH after liver transplantation has been reported [7].

\section{Case Presentation}

A 71 year-old woman with alcoholic cirrhosis presented to the emergency room and referred effort dyspnea for the last six months. She had a past medical history of ex-smoker (10 pack/year), glaucoma and hypothyroidism. She had been abstinent from alcohol for one year and showed no admissions for edematous-ascites syndrome, esophageal varices or spontaneous bacterial peritonitis. Her Model for End-Stage Liver Disease (MELD) score at the time of presentation to our center was 17 .

On physical exam, her breath sounds were clear and did not show signs of fluid overload. Cyanosis, clubbing or platypnea were not present, however orthodeoxia was detected: $\mathrm{SaO} 2$ of $93 \%(0.21)$ in supine position and $\mathrm{SaO} 2$ of $89 \%$ in upright position. Computer tomography scans showed ground glass areas with and thickening of interlobular septa. Laboratory evaluation showed: hematocrit $=41 \%$, hemoglobin $=14.5 \mathrm{~g} / \mathrm{dl}$, platelet count $=83000 / \mathrm{mm} 3$, total bilirubin $=2.7 \mathrm{~g} / \mathrm{dl}$, alkaline phosphatase $=118 \mathrm{U} / \mathrm{l}$, serum albumine $=4.1 \mathrm{~g} /$ $\mathrm{dl}$, aspartate aminotransferase $=30 \mathrm{UI} / \mathrm{l}$ and alanine aminotransferase $=43 \mathrm{UI} / \mathrm{l}$. HIV serology was negative and her immunological profile inconsistent with collagen diseases.

Pulmonary function, respiratory gas exchange and ventilationperfusion relationships were studied. Both forced spirometry results and lung volumes by plethysmography were normal. A severely reduced DLCO (37\%) after adequate correction for anaemia was detected (Table 1).

Arterial blood gas (ABG) on room air revealed a $\mathrm{pH}$ of 7.43 , partial pressure of oxygen $(\mathrm{PaO} 2)$ was $57.7 \mathrm{mmHg}$, partial pressure of dioxide $(\mathrm{PaCO} 2)$ was $30 \mathrm{mmHg}$, and an alveolar arterial gradient of $43 \mathrm{mmHg}$. Contrast enhanced transesophageal echocardiography 
Table 1: Characteristics of pulmonary function, respiratory gas exchange and ventilation-perfusion relationships.

\begin{tabular}{|l|l|}
\hline FVC $(\%$ predicted) & $1.89(80 \%)$ \\
\hline FEV1(\% predicted) & $1.38(78 \%)$ \\
\hline FEV1/FVC & 73 \\
\hline TLC liters & $4.50(104 \%)$ \\
\hline DLCO $\mathrm{ml} / \mathrm{min} / \mathrm{mmHg}(\%$ predicted) & $7.80(39 \%)$ \\
\hline DLCO cor $\mathrm{ml} / \mathrm{min} / \mathrm{mmHg}$ & $7.67(39 \%)$ \\
\hline $\mathrm{PaO} 2 \mathrm{mmHg}(\mathrm{room}$ air $)$ & 58 \\
\hline $\mathrm{PaCO} 2 \mathrm{mmHg}$ & 30 \\
\hline PaO2 $\mathrm{mmHg}(100 \%$ O2) & 309 \\
\hline Shunt & 18 \\
\hline
\end{tabular}

Abbreviations: FEVr: Forccd Expiratory Volume at $1 \mathrm{~s}$; FVC: Forced Vital Capacity; TLC: Total Lung Capacity; DLco. Single-breath carbon monoxide diffusing. Capacity; Pa02: arterial PO2; PaCO2: arterial PCO2 Shunt: percentage of blood flow to unventilated units.

(cTEE) revealed extra cardiac shunt (Figure 1). Shunt calculated was $18 \%$. The RHC showed a mean pulmonary arterial pressure (MPAP) of $28 \mathrm{mmHg}$ and a pulmonary capillary wedge pressure (PCWP) of $11 \mathrm{mmHg}$.

During this hospitalization, we did not measure vascular resistance or cardiac output, so we decided to perform this study when the patient was discharged. The patient was stable during the 10 day hospital stay and then discharged with oxygen-therapy. Three months later, a new contrast enhanced TEE was performed and the pulmonary systolic pressure increased to $66 \mathrm{mmHg}$. Right Heart Catheterization (RHC) showed as mean pulmonary arterial pressure (PAPm) of $50 \mathrm{mmHg}$, wedge pressure of $13 \mathrm{mmHg}$, pulmonary vascular resistance (PVR) of $789 \mathrm{dyns} / \mathrm{seg} / \mathrm{cm} 2$ and a cardiac index of $3,75 \mathrm{l} / \mathrm{min} / \mathrm{m} 2$. This evidence supported the diagnosis of severe portopulmonary hypertension.

Lung perfusion scan with $99 \mathrm{mTc}$ macro-aggregated albumin showed low probability of pulmonary thromboembolism (Figure 2).
She began treatment with sildenafil ( $25 \mathrm{mg}$ each 8 hours), but stopped it on the 4th day for headaches, flushing and increase of dyspnea. For this reason, she began treatment with ambrisentan 5 $\mathrm{mg} /$ daily, transaminases and arterial pressure levels did not increase and did clinically well.

This patient is assisted as an outpatient and is stable from hepatic dysfunction and dyspnea. Currently, she is waiting for new evaluation by liver transplant.

\section{Discussion}

Patients with HPS and POPH are rarely reported [8]. The first case was reported in 1999 by Martinez-Pall and coworkers [9]. Recently, Zopey and coworkers described a series of three non-transplanted patients: one of them improved with ambrisentan (similar treatment to our patient) and was added to the hepatic transplant waiting list [10].

HPS is characterized by hypoxemia, vascular pulmonary dilatation and hepatic disease1. Prevalence of HPS in patients on liver transplant waiting list is estimated at $20 \%$. The main symptom is effort dyspnea, usually with a history of alcoholic cirrhosis. Patients with HPS show normal spirometry with moderate to severe decrease of DLCO. Classification is performed using oxemia levels: mild is defined as $\mathrm{PaO} 2>80 \mathrm{mmHg}$, moderate as $80-60 \mathrm{mmHg}$, severe as 50 $60 \mathrm{mmHg}$ and very severe as $<50 \mathrm{mmHg}$ [11]. Patients presented in this case had a severe HPS pattern. She got hepatic transplant criteria except for MELD. The complementary method recommended to detect pulmonary vascular dilatation is contrast-enhanced TTE (CETTE) and lung perfusion scan with Tc99 (Tecnecio 99) [12].

Liver transplant is recommended for HPS patients with hypoxemia ( $\mathrm{PaO} 2$ between $60-50 \mathrm{mmHg}$ ), but not for patients with $\mathrm{PaO} 2<50 \mathrm{mmHg}$ because of proven poor results in these cases.

POPH is defined as pulmonary hypertension associated with portal hypertension whether or not portal hypertension is secondary to hepatic disease. Diagnosis is based on the pressure obtained by a $\mathrm{RHC}$ with MPAP $>25 \mathrm{mmHg}$, pulmonary arterial occlusion pressure

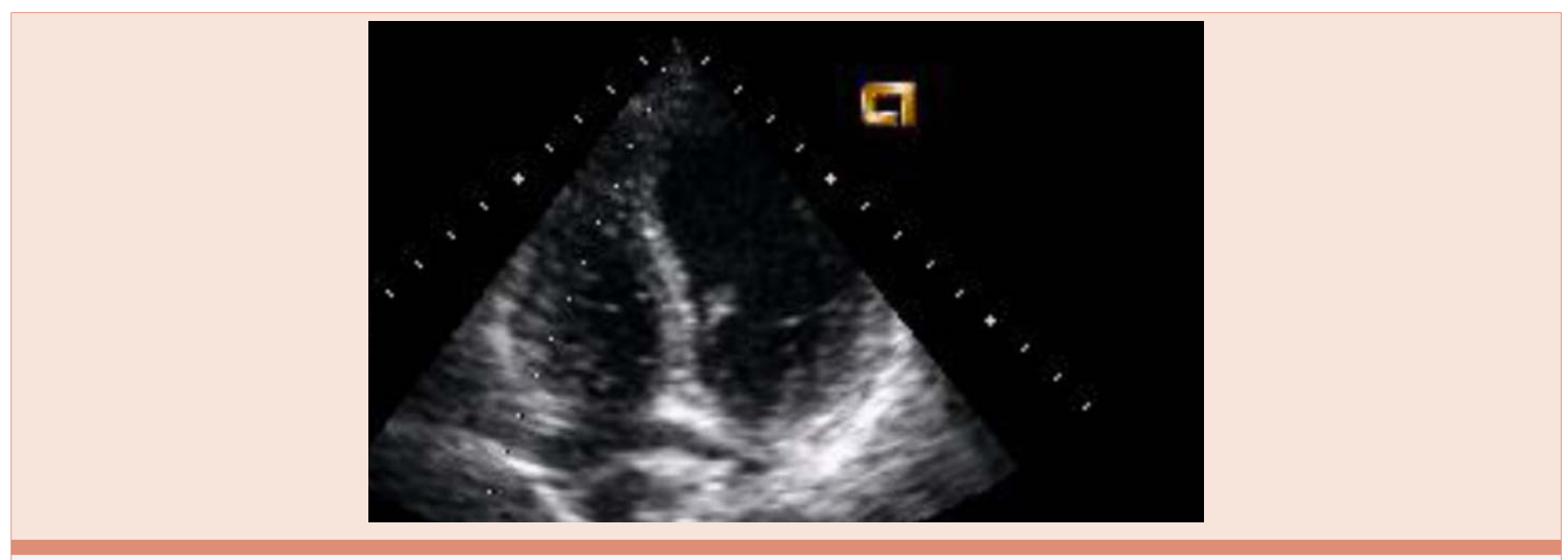

Figure 1: Transthoracic echocardiogram: Appearance of micro bubbles in the left atrium after 6 beats from opacification with shunt extra cardiac. Mention the title and explanation of figure. 


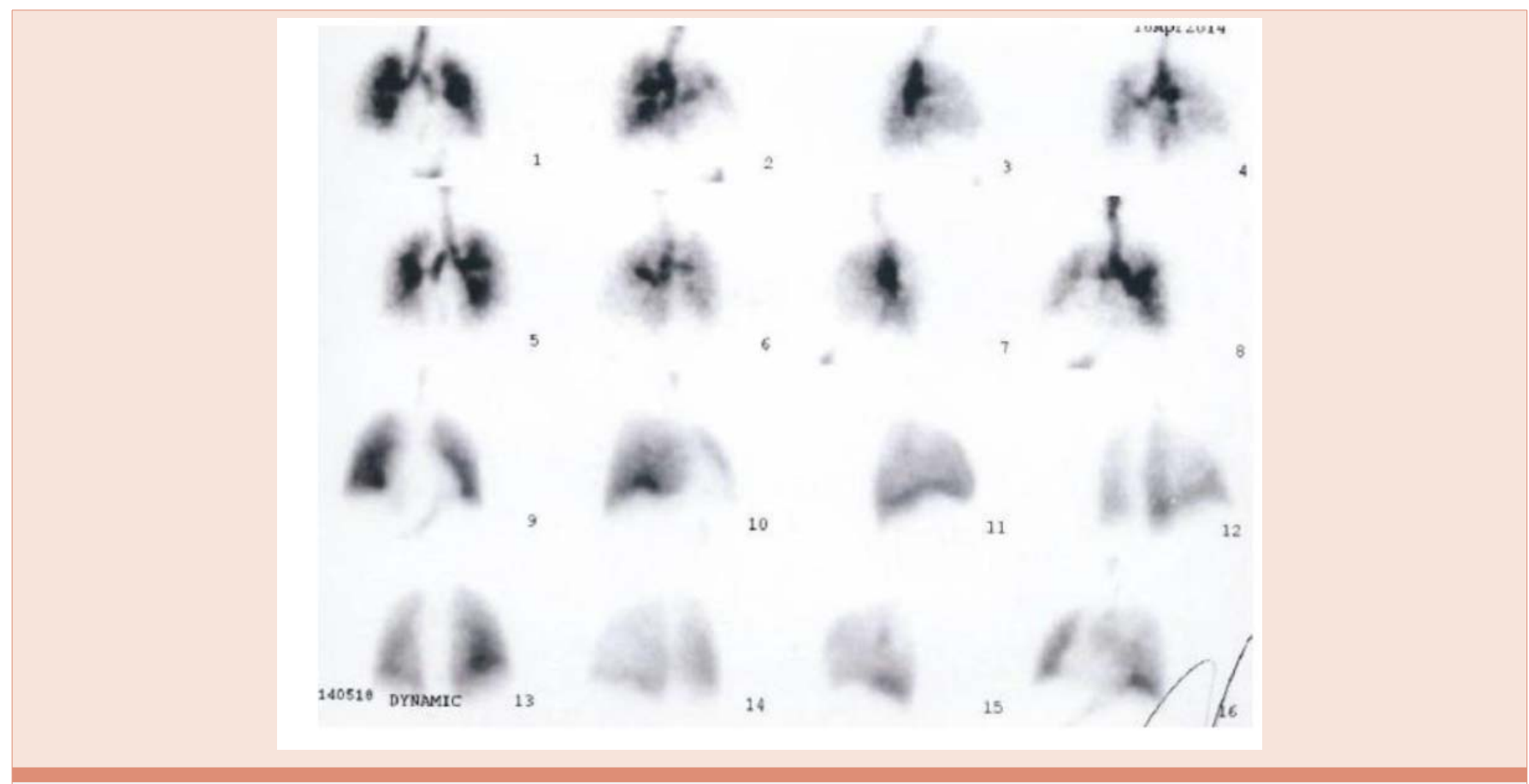

Figure 2: Technetium-99m macro aggregation albumin lung perfusion scan: We observed a rise in the lung perfusion in the bases, as findings suggestive of Pulmonary Hypertension. We did not observed abnormalities in the ventilation. This V/Q scan was interpreted as low probability of pulmonary embolism.

of $(\mathrm{PAOP})<15 \mathrm{mmHg}$ and an increase in pulmonary vascular resistance of $(\mathrm{PVR})>240 \mathrm{dyns} / \mathrm{seg} / \mathrm{cm}-5$. POPH is classified as mild ( $\mathrm{mPAP}>25<35 \mathrm{mmHg}$ ), mild to moderate (mPAP $35-45 \mathrm{mmHg}$ ) and severe (MPAP $>45 \mathrm{mmHg}$ ). The estimated prevalence reported is variable, between $2.5 \%$ and $8.5 \%$, in patients on liver transplant list [13].

Physiology of $\mathrm{PPOH}$ is characterized by vascular alteration that leads to increased vasoconstriction and remodeling of pulmonary arterial bed including small vases vessels. Symptoms usually have insidious onset and are nonspecific. Patients refer effort and rest dyspnea and show signs of right heart failure. Screening is performed with CTEE which has shown high sensitivity but low specificity. Systolic pressure of left ventricle (SPLV) $<30 \mathrm{mmHg}$ could contribute to rule out HPS, however SPLV $>50 \mathrm{mmHg}$ is used to confirm moderate to severe HPS. A SPLV $<38 \mathrm{mmHg}$ has recently been proposed to limit the number of false positives. Lung perfusion scan and High Resolution Computed Tomography with contrast and thin slides could confirm pulmonary thromboembolism. Lung catheterization is required to define diagnosis [14]. Conventional treatment consists of fluid overload with diuretics and oxygen but does not improve survival rate [15]. Inhibitors of 1-endothelin as bosentan are an effective treatment in stable hepatic illness, however there is insufficient evidence of its effectiveness in patients with altered hepatic dysfunction [16]. Furthermore, patients treated with bosentan have shown better results in hemodynamic parameters and the 6 minute-walk distance test (6MWD) compared with patients treated with inhaled iloprost [17]. It has been demonstrated that treatment with ambrisentan has less hepatic toxicity and improves hemodynamic parameters with respect to bonsentan [18]. Patients with HSP could be treated with inhaled iloprost, which improves $6 \mathrm{MWD}$ and the hepatic function. Sildenafil is the best option to improve POPH because it maintains hemodynamic parameters [19].

\section{References}

1. Rodriguez-Roisin R, Krowka MJ, Hervé P, Fallon MB (2004) Pulmonaryhepatic vascular disorders (PHD). Eur Respir J 24: 861-880

2. Porres-Aguilar M, Altamirano JT, Torre-Delgadillo A, Charlton MR, DuarteRojo A (2012) Portopulmonary hypertension and hepatopulmonary syndrome: a clinician-oriented overview. Eur Respir Rev 21: 223-233.

3. Huffmyer JL, Nemergut EC (2007) Respiratory dysfunction and pulmonary disease in cirrhosis and other hepatic disorders. Respir Care 52: 1030-1036.

4. Mandell MS, Groves BM (1996) Pulmonary hypertension in chronic liver disease. Clin Chest Med 17: 17-33.

5. Espinosa MD, Nogueras F, Olmedo C, Macias R, Muffak-Granero K, et al. (2012) Hepatopulmonary syndrome among cirrhotic candidates for liver transplantation. Transplant Proc 44: 1508-1509.

6. Gómez FP, Martínez-Pallí G, Barberá JA, Roca J, Navasa M, et al. (2004) Gas exchange mechanism of orthodeoxia in hepatopulmonary syndrome. Hepatology 40: 660-666.

7. Raevens S, Colle I, Reyntjens K, Geerts A, Berrevoet F, et al. (2013) Echocardiography for the detection of portopulmonary hypertension in liver transplant candidates: an analysis of cutoff values. Liver transplantation 19: 602-610.

8. Krowka MJ, Porayko MK, Plevak DJ, Pappas C, Steers JL, et al. (1997) Hepatopulmonary syndrome with progressive hypoxaemia as an indication for liver transplantation: case reports and literature review. Mayo Clin Proc 72: $44-53$.

9. Martinez-Pall G, Barbera JA, Taura P, Cirera I, Visa J, et al. (1999) Severe portopulmonary hypertension after liver transplantation in a patient with preexisting hepatopulmonary syndrome. Journal of Hepatology 31: 10751079. 
10. Zopey R, Susanto I, Barjaktarevic I, Wang T (2013) Transition from hepatopulmonary syndrome to portopulmonary hypertension: a case series of 3 patients. Case Rep Pulmonol 2013: 561870

11. Golbin JM, Krowka MJ (2007) Portopulmonary hypertension. Clin Chest Med 28: 203-218.

12. Abrams GA, Jaffe CC, Hoffer PB, Binder HJ, Fallon MB (1995) Diagnostic utility of contrast echocardiography and lung perfusion scan in patients with hepatopulmonary syndrome. Gastroenterology 109: 1283-1288.

13. Herve' P, Lebrec D, Brenot F, Simonneau G, Humbert M, et al. (1998) Pulmonary vascular disorders in portal hypertension. Eur Respir J 11: 1153 1166.

14. Golbin JM, Krowka MJ (2007) Portopulmonary hypertension. Clin Chest Med 28: 203-218.

15. Savale L, O'Callaghan DS, Magnier R, Le Pavec J, Hervé P, et al. (2011)
Current management approaches to portopulmonary hypertension. Int J Clin Pract 65: 11-18.

16. Hoeper MM, Halank M, Marx C, Hoeffken G, Seyfarth HJ, et al. (2005) Bosentan therapy for portopulmonary hypertension. Eur Respir J 25: 502508.

17. Hoeper MM, Seyfarth HJ, Hoeffken G, Wirtz H, Spiekerkoetter E, et al. (2007) Experience with inhaled iloprost and bosentan in portopulmonary hypertension. Eur Respir J 30: 1096-1102.

18. Cartin-Ceba R, Swanson K, Lyer V, Wiesner RH, Krowka MJ (2011) Safety and efficacy of ambrisentan for the treatment of portopulmonary hypertension. Chest 139: 109-114.

19. Reichenberger F, Voswinckel R, Steveling E, Enke B, Kreckel A, et al. (2006) Sildenafil treatment for portopulmonary hypertension. Eur Respir J 28: 563567.

Copyright: (c) 2016 Ernst G, et al. This is an open-access article distributed under the terms of the Creative Commons Attribution License, which permits unrestricted use, distribution, and reproduction in any medium, provided the original author and source are credited.

Citation: Ernst G, Grassi F, Chertcoff JF (2016) Hepatopulmonary Syndrome and Portopulmonary Hypertension in the Same Patient. J Clin Microbiol 